\title{
¡NUESTRA LUCHA ES POR LA VIDA! APUNTES CRÍTICOS SOBRE LA REORGANIZACIÓN CAPITALISTA DE LA CONDICIÓN DE INTERDEPENDENCIA ${ }^{1}$
}

\begin{abstract}
Resumen
Este artículo se divide en dos partes. En la primera, propongo entender la reproducción de la vida a partir de la noción de interdependencia, para pasar a indagar en las características que tienen las relaciones que como humanos tejemos con los entornos que habitamos. En la segunda, planteo, a partir de una deconstrucción de la noción de naturaleza, una crítica a la dimensión simbólica y afectiva inscrita en la dinámica capitalista de reorganización de la condición de interdependencia. Concluyo el artículo, con una hipótesis dirigida a explorar la potencia transformadora inscrita en las luchas en defensa de la vida que se despliegan hoy en Abya Yala ${ }^{2}$.

Palabras claves: trama de la vida, condición de interdependencia, separación ser humano-naturaleza, luchas en defensa de la vida.

\section{NOSSA LUTA É PELA VIDA! APONTAMENTOS CRÍTICOS SOBRE A REORGANIZAÇÃO CAPITALISTA DA CONDIÇÃO DE INTERDEPENDÊNCIA}

Lucia Linsalata ${ }^{2}$

\section{Resumo}

Este artigo se divide em duas partes. Na primeira parte, proponho entender a reprodução da vida a partir da noção de interdependência, para passar a indagar sobre as características das relações que como humanos tecemos com os entornos que habitamos. Na segunda parte apresento - a partir de uma desconstrução da noção de natureza - uma crítica à dimensão simbólica e afetiva inscrita na dinâmica capitalista de reorganização da condição de interdependência. Concluo o artigo com uma hipótese, dirigida a explorar a potência transformadora inscrita nas lutas em defesa da vida que se desdobram hoje na Abya Yala ${ }^{3}$.

Palavras-chave: teia da vida; condição de interdependência; separação ser humano-natureza; lutas em defesa da vida.

\section{OUR STRUGGLE IS FOR LIFE! CRITICAL NOTES ON THE CAPITALIST REORGANIZATION OF THE INTERDEPENDENCE'S CONDITION}

\section{Abstract}

This article is divided into two parts. In the first one, I propose to understand life's reproduction basing me on the concept of interdependence's condition, in order to investigate the characteristics of the relations that, as humans, we weave with the environments we inhabit. In the second one, based on a deconstruction of the notion of nature, I propose a critique on the symbolic and affective dimension inscribed in the capitalist reorganization of the interdependence's condition. I conclude the article, with a hypothesis aimed at exploring the transformative power inscribed in the struggles in defense of life unfolding today in Abya Yala ${ }^{2}$.

Keywords: web of life, interdependence's condition, separation human-nature, struggles in defense of life.

\footnotetext{
1 Artigo recebido em 31/01/2020. Primeira avaliação em 18/02/2020. Segunda avaliação em 13/02/2020. Terceira avaliação em 20/02/2020. Aprovado em 31/03/2020. Publicado em 22/05/2020.

DOI: https://doi.org/10.22409/tn.v18i36.40580

2 Profesora investigadora del Posgrado de Sociología del Instituto de Ciencias Sociales "Alfonso Vélez Pliego" de la Benemérita Universidad Autónoma de Puebla. Correo electrónico: lucia.linsalata@gmail.com. ORCID: 0000-0002-2845-6988.

${ }^{3}$ En la lengua del pueblo Kuna de la costa de Panamá, Abya Yala significa "tierra madura", "tierra viva" o "tierra en florecimiento" y es sinónimo de América. Dicho término ha sido adoptado y re-apropiado por múltiples organizaciones, comunidades e instituciones indígenas de todo el continente para referirse al territorio continental, en contraposición al término colonial "América". Su uso ha implicado un proceso de resignificación identitaria de los territorios americanos por parte de los pueblos originarios. Por ello, decidí adoptarlo en este artículo en lugar del término colonial "America".
} 
En memoria de Samir Flores Soberanes.

¡Samir vive, la lucha sigue!

Äjte' te' dzundy

mokaya'

mojk'jäyä

Kedgä'kätpatzi jojmorambä äj'

nwirun'jindam

ngobigbatzi äj' dzokoyjin tumdumäbä

tämbu

jindire' suñ'gomujsibätzi yä' Nasakobajk

Nä' tzambatzi te' kotzojk' komi

ojnayajpatzi jach'tanä'ram

Dzemiajpatzi te' joyjoyeram'

aj' ore' maka yayi'angas

mumu'is yajk' mujsä juche nkätu äj' iri yä'

Nasakobajkäjsi
Soy sembradora,

Protectora de esta tierra,

la flor del maíz.

Observo con mis ojos antiguos,

Elijo con el corazón cada semilla, no es en balde mi conocimiento del mundo.

Converso con el dueño del cerro,

riño con las plantas malignas.

Soy la provocadora de los seres invisibles, mi voz se escucha hasta los confines de las montañas, porque nadie podrá negar mi paso por el Universo.

(Sánchez Gomez, 2013)

Escuché por primera vez estos versos de la voz de su joven autora, Mikeas Sánchez Gómez, en un acto contra los proyectos mineros e hidrocarburíferos que amenazan hoy el territorio del pueblo Zoque, en el estado de Chiapas (México). Mikeas es una extraordinaria poetiza zoque, hija de una gran narradora de leyendas tradicionales y nieta de un poderoso chamán. Como muchas mujeres y hombres de Abya Yala, Mikeas no ha perdido la costumbre de sembrar la tierra, hablar con los cerros y las plantas en lengua materna, y recordar e invocar la sabiduría de los ancestros con la fuerza de la metáfora que habita su idioma.

Como muchas otras mujeres y hombres de su pueblo y de otros pueblos de Abya Yala, Mikeas está hoy en pie de lucha. Lucha para defender su territorio de los "proyectos de muerte" que hoy lo amenazan. Y, mientras lucha, recita sus poemas, para mantener viva la memoria de su pueblo y combatir el olvido, la violencia y la desafección que llegan con los proyectos.

Lucha Mikeas, luchan los pueblos, luchan las mujeres y los hombres que habitan las distintas coordenadas y las múltiples geografías de este continente. Y, cuando se les pregunta porqué luchan, muchas, muchos contestan: "¡Nuestra lucha es por la vida!".

¿Qué significa defender la vida hoy en Abya Yala? ¿Qué se defiende cuando se defiende un río, un lago, un cerro, un bosque, un desierto sagrado, un manantial, unas semillas originarias, un territorio común, una trama relacional o un modo de 
existir, de los renovados y cada vez más violentos procesos de separación y despojo impuestos por la voracidad del capital? ¿Qué se está disputando en aquellas luchas que están poniendo la defensa de la vida humana y no humana en el centro de su discurso y de su práctica política? ¿Qué posibilidades de transformación social se están abriendo a partir del despliegue de dichas luchas?

La centralidad que la noción de vida ha adquirido en una multiplicidad de luchas que hoy se despliegan a lo largo y ancho de toda Abya Yala, nos obliga a volver a colocar la reproducción de la existencia (humana y no humana) en el centro del debate y a profundizar nuestra reflexión, tanto en torno a la forma en que, desde el capital y el orden simbólico dominante, se están amenazando, re-estructurando e invisibilizando las tramas de interdependencia que sostienen la vida; como en torno a las potencias transformadoras inscritas en las luchas de aquellos pueblos que no han dejado de disputar por otros sentidos de vida y otros términos de reproducción de la misma.

En este artículo, intento contribuir a este desafío. Empiezo el texto proponiendo entender la reproducción de la vida a partir de la condición de interdependencia, para pasar a indagar, en un segundo momento, en las características que tienen las relaciones de interdependencia que como humanos tejemos entre nosotros, con otros seres vivos y con la materialidad toda que constituyen nuestros entornos. A partir de este primer acercamiento analítico, propongo algunas reflexiones dirigidas a plantear una crítica a la dimensión simbólica y afectiva inscrita en la dinámica capitalista de reorganización continua y permanente de la condición de interdependencia. En particular, intento demostrar como la noción occidental de naturaleza y la separación que la cosmovisión moderno-occidental establece entre ser humano y naturaleza, ha operado y sigue operando en nuestras sociedades como un poderoso dispositivo semántico de negación de la violencia expropiatoria inscrita en la dinámica capitalista de acumulación y como un igualmente eficaz dispositivo de regulación del dolor social que dicha dinámica ha infligido históricamente sobre los cuerpos humanos y no humanos de vastos territorios del planeta.

Tal dispositivo de negación de la violencia y regulación del dolor social, al tiempo de ocultar la raíz colonial, antropocéntrica y patriarcal del orden simbólico 
que sostiene al del mundo moderno-capitalista, invisibiliza permanentemente las complejas relaciones de interdependencia que sostienen la vida en los territorios y el modo en que éstas han sido significadas, tejidas y cultivadas desde otras epistemes, otras afectividades, otras subjetividades, distintas a las impuestas por la modernidad capitalista. Tales subjetividades otras, como las que emergen en los versos de Mikeas y en una multiplicidad de luchas en defensa de la vida que se despliegan hoy a lo largo y ancho de Abya Yala, están poniendo en crisis el orden simbólico dominante, al tiempo que nos están ofreciendo la posibilidad civilizatoria de desplazar nuestras subjetividades, transformar las estructuras del sentir de nuestras sociedades y replantear radicalmente los términos bajo los cuales, en los mundos moderno-capitalistas, hemos estado tejiendo nuestras relaciones de interdependencia en la trama de la vida.

Mas procedamos con orden, empecemos aclarando a qué me refiero cuando hablo de condición de interdependencia.

\section{Interdependemos, por tanto existimos}

La interdependencia, como lazo que nos ata a los otros, se encuentra en el corazón de toda vida [...] aún habitando en la dispersión, nadando entre diferencias, perdiéndonos entre relatos fragmentados, no existe vida posible sin esa dimensión común de la existencia.

(GIL, 2011:39-40)

En diálogo con la economía feminista, parto de la convicción de que no podemos pensar la reproducción de la vida en términos individuales, ni mucho menos a partir de la noción moderno capitalista y heteropatrialcal de autosuficiencia (PÉREZ OROSCO, 2014). El mito del homo economicus autosuficiente es una de las fantasías más perversas del pensamiento económico moderno. Su construcción se ha erigido sobre la naturalización de las condiciones de explotación y desigualdad que sostienen las leyes de la acumulación capitalista, así como sobre la negación sistemática de los vínculos de interdependencia que nos unen unos a otros, incluyendo a otros seres vivos y al planeta en su conjunto. Más allá de los procesos de individuación modernos y de los dispositivos de negación que los sostienen y reproducen, la vida, tanto humana como no humana, no puede ser 
comprendida como la simple suma de seres individuales e independientes los unos de los otros; tampoco puede entenderse, ni mucho menos sostenerse, a nivel de una sola especie o de un solo ecosistema (NAVARRO TRUJILLO, 2017; HERNÁNDEZ HERNÁNDEZ, 2019: 38). La vida se hace en interdependencia. Es ésta una condición ineludible y contingente de toda existencia en el planeta tierra. Interdependemos, por tanto existimos. ¿Cómo entender la condición de interdependencia? ¿Qué implicaciones tiene pensar la reproducción de la vida desde las tramas de interdependencia que la posibilitan?

El famoso físico austriaco Fritjof Capra, quien ha dedicado buena parte de su labor teórica a la construcción de una comprensión sistémica de la vida y a la superación radical de toda visión cartesiana y mecanicista de la misma, nos brinda algunas pistas para aproximarnos a una respuesta. Al explicar la condición de interdependencia desde una perspectiva ecosistémica, escribe:

Todos los miembros de una comunidad ecológica se hallan interconectados en una vasta e intrincada red de relaciones, la trama de la vida. Sus propiedades esenciales y, de hecho, sus misma existencia se derivan de estas relaciones. El comportamiento de cada miembro viviente dentro de un ecosistema depende del comportamiento de muchos otros. [...] Comprender la interdependencia ecológica significa comprender relaciones. Esta comprensión requiere los cambios de percepción característicos del pensamiento sistémico: de las partes al todo, de objetos a relaciones, de contenido a patrón. (CAPRA, 1999:196-197).

Existen múltiples diferencias entre comunidades humanas y ecosistemas. Sin embargo, en ambas, la vida se reproduce a partir de un patrón de organización básico: el de la red (CAPRA, 1999) ${ }^{4}$. Lo anterior, siguiendo a Capra, implica entender que las relaciones que sostienen y posibilitan la reproducción de la vida, tanto humana como no humana, no son lineales, no siguen un patrón de causa-

\footnotetext{
${ }^{4}$ En "La trama de la vida", Capra explica la idea que acabamos de enunciar con las siguientes palabras "¿hay un patrón de organización común que pueda ser identificado en todos los seres vivos? Veremos que efectivamente, así es. Este patrón de organización, común a todos los seres vivos, será analizado en detalle más adelante. Su propiedad más importante es que se trata de un patrón en forma de red. Dondequiera que encontremos sistemas vivos -organismos, partes de organismos o comunidades de organismos-, podemos observar que sus componentes están dispuestos en red. Si vemos vidas, vemos redes. [...] La primera y más obvia propiedad de cualquier red es su no-linealidad, va en todas direcciones. Por tanto las relaciones en un patrón de red son relaciones no-lineales. En particular, un estimulo o mensaje puede viajar en un camino cíclico que puede convertirse en un bucle de retroalimentación. El concepto de retroalimentación está íntimamente ligado al de patrón de red" (CAPRA, 1999: 58-59).
} 
efecto; suponen, por lo contrario, bucles constantes de retroalimentación y dinámicas complejas de asociación, cooperación y co-evolución, tanto entre organismos vivos, como entre éstos y el entorno abiótico que habitan.

En tal sentido, la trama de la vida es mucho más que la simple suma de sus partes; es una red multidimensional de redes relacionales interconectadas entre sí e inmersas en un proceso autopoiético en continuo devenir, marcado por el fluir incesante de materia y energía a través de los organismos vivos y sus entornos. No existe una relación de independencia entre los múltiples organismos vivos y entre éstos y el medio abiótico en y con el cual se reproducen; sino un articulado subseguirse de intercambios metabólicos: un fluir constante de materia y energía que interconecta unos a otros y al todo en su conjunto. Tampoco existe una Naturaleza en singular, "un estado natural y trascendental de las cosas transhistórico y/o trans-geográfico" (SWYNGENDOUW, 2011: 45) a partir del cual los organismos vivos se reproducen; sino un tejido de infinitas y heterogéneas combinaciones de relaciones socio-ecológicas siempre situadas en el espaciotiempo y sujetas a transformaciones constantes. Tal como afirma Swyngendouw, de la mano de Levins y Lewontin:

[...] el mundo biológico está intrínseca y relacionalmente constituido a través de modos infinitamente variables, contingentes y producidos históricamente, en los cuales cada parte, humana o no humana, orgánica o inorgánica, está conectada de forma indisoluble con las relaciones más amplias que construyen el todo (Ibídem: 46).

Las comunidades humanas pueden distinguirse de otras comunidades bióticas por múltiples elementos, (el pensamiento abstracto, el lenguaje verbal, la cultura, etc.), mas ninguna de ellas puede eludir esta condición básica de la existencia: interdependemos; estamos intrínsecamente relacionados con los otros seres y la materialidad toda que constituye nuestros entornos; nos transformamos mutuamente; co-evolucionamos "en formas históricamente contigentes, altamente diversificadas, localmente específicas y a menudo imposibles de aprender en su totalidad" (Ibídem).

Aclarado lo anterior, preguntémonos ahora: ¿de qué forma los humanos habitamos y nos hacemos en la trama de la vida? ¿qué características tienen las relaciones de interdependencia que como humanos tejemos entre nosotros, con otros seres vivos y con la materialidad toda que constituyen nuestros entornos? 
En las siguientes páginas, intentaré distinguir analíticamente tres dimensiones cualitativas que caracterizan las relaciones de interdependencia que como humanos tejemos entre nosotros y con el mundo no humano en y con el cual reproducimos nuestras existencias. Éstas son: la dimensión simbólica, la dimensión política y la dimensión afectiva. Al proponer esta primera diferenciación, aclaro de antemano que, en el proceso de reproducción de la vida humana, tales dimensiones están estrechamente imbricadas la una con la otra y se determinan mutuamente. La distinción que propongo, en tal sentido, es pura y exclusivamente analítica y, como veremos más adelante, tiene la finalidad de visibilizar aquello que el orden simbólico moderno capitalista, a partir de su raíz profundamente colonial, patriarcal y antropocéntrica, oculta sistemáticamente.

\section{Tres dimensiones humanas de la condición de interdependencia}

Desde por lo menos 50.000 años a.C., fecha en la que la comunidad científica data la aparición de los primeros grupos de la especie Homo sapiens en el planeta tierra, las y los sapiens vivimos en mundos construidos simbólicamente. Pues, una de nuestras principales características es la capacidad de construir representaciones simbólicas que nos permiten dotar de "trascendencia" a la dimensión material perceptible en la que estamos inmersos (HERNANDO, 2012: 61-62). La capacidad simbólica es definitivamente uno de los elementos característicos del proceso de cognición en la especie humana.

¿Por qué? ¿Qué es el proceso de cognición y cómo se da en los humanos? La palabra cognición deriva del latín cognitio y significa "efecto y acción de conocer completamente". Siguiendo la propuesta que Javier Hernández elabora a partir del diálogo con Capra, Maturana y Varela, el proceso de cognición “implica percepción (del medio externo), emoción (procesamiento al interior de la estructura del organismo de la información obtenida del exterior) y acción o comportamiento (movimiento hacia condiciones físicas favorables de reproducción)" (HERNÁNDEZ HERNÁNDEZ, 2019: 42). Dicho proceso está presente en todos los seres vivos, incluso en los que no poseen cerebro ni sistema nervioso central. Tal como indica su etimología, implica simultáneamente un efecto y una acción: el efecto derivado de la percepción, es decir, "de la estimulación por parte de alguna fuerza externa 
sobre algún elemento de la estructura del organismo vivo” (Ibídem); y una acción, que se concreta "en el proceso de incorporación y asimilación de materia y energía del exterior" (Ibídem) que el organismo vivo pone en marcha en su interior a partir de la transformación de su red neuronal. En tal sentido, el proceso de cognición no puede ser concebido como la simple representación de una realidad externa por parte del organismo vivo; sino que tiene que ser entendido como la creación constante de nuevos procesos y relaciones al interior de su red neuronal, como un proceso autopoiético en el que cada organismo, al percibir el mundo externo y al entablar una relación con éste, se hace a sí mismo (CAPRA, 1999: 68-69)

En el caso de los humanos, el proceso de cognición pasa por un sistema nervioso complejo que, como sabemos, tiene dos componentes, el periférico y central. El central está compuesto por un cerebro que se caracteriza por la presencia de lenguaje articulado, pensamiento conceptual, capacidad de abstracción, imaginación y simbolización, entre otras cosas. En un ejemplo. A diferencia de otros seres vivos, los seres humanos no sólo percibimos la luz del sol y ponemos en marcha una serie de reacciones físico-químicas y de transformaciones ante dicha percepción al interior de nuestra red neuronal, también tenemos la capacidad de comprender y trasmitir socialmente, a través del uso del lenguaje verbal y del pensamiento abstracto, el funcionamiento del sol, de la energía que percibimos y de todas las reacciones físico-químicas que se producen en nosotros. Además de lo anterior, podemos utilizar y transformar intencionalmente la energía solar para satisfacer necesidades socialmente construidas como generar relojes solares, deshidratar alimentos, crear paneles para la producción de energía electrica, etc. Más aún, en la historia humana, no ha habido una única manera de explicar el funcionamiento de la energía solar o de utilizarla para la satisfacción de necesidades socialmente construidas, sino múltiples sistemas de creencias y prácticas sociales relacionadas con la misma. En Abya Yala, por ejemplo, el sol ha sido objeto de culto para una multiplicidad de pueblos; cada uno de los sistemas de creencias y de las prácticas de culto asociadas al sol corresponden a procesos culturales complejos, histórica y geográficamente situados de los que, las comunidades humanas protagonistas de dichas creencias, no pueden prescindir, en la medida en que son constitutivos de las mismas y de las capacidades cognitivas de todos sus miembros. 
Finalmente, para el ser humano (que, como he venido sosteniendo, no puede ser concebido como "individuo" aislado sino como un ser interdependiente, histórica y geográficamente situado e intrínsecamente relacionado con el entorno biótico y abiótico en y con el cual co-produce y reproduce su vida) reproducirse, producir y consumir la forma práctica de su existencia, no equivale a repetirla o reiterarla automáticamente, sino a crearla y reinventarla constantemente, a través de un proceso permanente de codificación y apropiación simbólica del conjunto de relaciones de intercambio, interdependencia y mutua transformación que entabla, tanto con los miembros de su misma especie, como con el entorno biótico y abiótico en y con el cual reproduce su vida (GUTIÉRREZ, LINSALATA, NAVARRO, 2016: 381).

Para reproducir nuestras existencias interdependemos de otros, de otros seres humanos, de otros seres vivos y de la materialidad inorgánica que nos rodea. Tejemos intencionalmente e inintencionalmente vínculos con el mundo que nos rodea y nos hace; lo producimos activamente, lo transformamos y, al producirlo, nos producimos y transformamos a nosotros mismos tanto en términos materiales como simbólicos, lo uno no existiría sin lo otro. Tal como sostiene Bolívar Echeverría, en el proceso humano de la reproducción social, existe una identidad esencial entre el proceso de producción/consumos de objetos prácticos y el proceso de producción y consumo de significaciones (ECHEVERRÍA, 2001: 96). Para el ser humano, producir y consumir su existencia implica significarla a través de un proceso continuo y renovado de construcción y apropiación simbólica y semiótica del mundo. Dicho proceso, no se produce en términos generales y/o transhistóricos, sino que adquiere existencia "en las distintas estructuraciones concretas de su realización efectivas" (ECHEVERRÍA, 2001: 131). Es decir, todo proceso humano de reproducción práctica y simbólica de la vida se identifica y singulariza en una historia concreta. No existe algo al que pudiéramos nombrar en singular el proceso de la reproducción de la vida humana, sino múltiples concresiones prácticas y simbólicas de la misma.

Ahora bien, reconocer la dimensión simbólica de lo humano y sus múltiples concreciones históricas, nos lleva directamente a reconocer otra dimensión esencial de la condición de interdependencia en las comunidades humanas, aquella 
dimensión que Bolívar Echeverría llama la politicidad básica del proceso de la reproducción social o lo político (ECHEVERRÍA, 1998).

En diálogo con el filosofo ecuatoriano, entendemos lo político como la capacidad de los seres humanos de dar una forma singular, siempre contingente e inestable, a su socialidad y al conjunto de las relaciones de interdependencia que tejen con el mundo que los rodea. La capacidad de proyectar, crear y modificar constantemente las reglas de la convivencia humana; de moldear su organización social, dando forma, contenido y sentido a las relaciones de co-producción y codisfrute que interconectan y definen a los seres humanos en tanto sujetos sociales e interdependientes, posibilitando la reproducción de su existencia. En las palabras de Echeverría:

El sujeto social no puede sino cambiarse a sí mismo. Aun cuando
aparentemente no lo hace, cuando mantiene una misma forma y
respeta las mismas instituciones, el mismo orden social por largos
períodos, ello es resultado de una repetida ratificación de ese orden,
de una recreación o re-hechura del mismo. No hay posibilidad de un
verdadero automatismo -ni animal ni cibernético-en el sujeto social.
El ser humano está, como le gustaba decir a Sarte, "condenado a
su libertad", obligado a modificarse a sí mismo, aunque sea para
ratificar su forma tradicional. Tiene ante sí la "materia" que le
corresponde transformar, su propia socialidad; una materia cuya
peculiaridad está en que exige de él a cada paso que la sostenga
en su figura o que la ponga en otra (Echeverría 2001: 69).

El ser humano, para garantizar su existencia y reproducir su vida, necesita darse una forma con los otros, conformar su socialidad; y a través de ella, conformar su entorno, establecer una relación con lo no-humano, crear su propio mundo de vida. Tal capacidad de forma inscrita en los sujetos sociales se realiza en el tiempo y en el espacio, es decir, se actualiza y toma cuerpo en un sin número de comunidades singulares y concretas de vida, localizadas territorialmente, cuya diversidad da cuenta de la "inevitable" pluralidad y heterogeneidad de lo humano. Lo político, así entendido, como la capacidad de forma inscrita en el proceso de la reproducción social, no es una dimensión ente otras de la vida humana, sino una dimensión constitutiva de las relaciones de interdependencia a través de las cuales tejemos nuestras existencias y nuestra socialidad.

Un aspecto esencial de esa politicidad constitutiva del proceso humano de la reproducción social son las emociones y los sentimientos que la habitan y 
conforman, es decir, su dimensión afectiva ${ }^{5}$. De la mano de Sara Ahmed y de otras pensadoras feministas, entiendo que las emociones y los sentimientos humanos no son, tal como nos han propuesto pensar múltiples corrientes de la psicología, un simple asunto personal, una pura manifestación de la psique de la persona; sino prácticas culturales que se estructuran socialmente a través de circuitos afectivos (Ahmed, 2015: 32). Prácticas que, al tiempo de estructurarse socialmente, estructuran la piel del mundo en que vivimos y, por consecuencia, nuestra propia piel y nuestro accionar (o no accionar) al interior del mismo.

Tal como explica Ahmed, las emociones al igual que los sentimientos no residen de forma innata en los sujetos, sino que son producidos como efecto de la interacción entre sujetos y entre sujetos y objetos. Es a partir de las emociones que, como cuerpos individuales y colectivos que somos, percibimos en la interacción con los otros seres y la materialidad toda que constituye nuestro entorno, que podemos distinguir un afuera y un adentro y así delinear la superficie y los límites de aquello que percibimos como el yo y el nosotros, lo individual y lo social (Ibídem: 34).

A partir del movimiento y la interacción que conecta unos cuerpos con otros, las emociones producen las superficies y los límites que permiten que todo tipo de elemento sea delineado, y que incluso lo individual y lo social sean percibidos como objetos conocibles y moldeables. En tal sentido, las emociones dan forma al mundo, son constitutivas de la capacidad de forma que radica en el proceso de la reproducción social. Sin embargo, dicha capacidad de delineación no es inmediata, sino siempre mediada por un imaginario colectivo, por una interpretación culturalmente construida de lo que sentimos y de nuestra propia corporeidad.

Dicho en otras palabras, las emociones delinean al mundo y a nuestro accionar en él, pero el modo en que accionamos o no accionamos depende de las interpretaciones que de ellas hagamos y del modo en que éstas se transforman en sentimientos que perduran en los cuerpos, sean éstos individuales o colectivos. Lo que como humanos sentimos depende en gran medida de las interpretaciones que hagamos de nuestro sentir, y dichas interpretaciones no son estrictamente realizadas por nosotros, sino que nos anteceden en gran medida. Son parte de

\footnotetext{
${ }^{5}$ La reflexión que aquí se presenta surge del diálogo con el concepto de "dimensión sensible de lo político" propuesto por Ana Suárez Lima (2018).
} 
estructuras del sentir (Williams, 1980) producidas históricamente por comunidades concretas de vida; estructuras que nos han sido heredadas y trasmitidas a través de las comunidades afectivas que nos atraviesan y nos hacen, empezando por las comunidades afectivas que nos criaron. En las palabras de Machado:

Las emociones y los sentimientos, expresiones de cómo los cuerpos
y los espíritus son afectados por las relaciones y los entornos,
constituyen la unidad elemental de la condición política... Suelen ser
la soldadura entre lo 'personal' y lo 'social'; dan cuenta de cómo el
'cuerpo social' sella sus impresiones en los cuerpos-individuos
(MACHADO, 2014a: 66).

Tal como no podemos escindir lo que pensamos y conocemos de lo que sentimos, no podemos escindir lo que sentimos del modo en que estamos conformados (y nos seguimos conformando) social y culturalmente. Lo simbólico, lo político y lo afectivo, al igual que la dimensión bio-ecológica, son elementos indisolubles de la condición de interdependencia que sostienen nuestra existencia como especie humana en la trama de la vida.

Aclarado como pensamos la condición de interdependencia en la trama de la vida, pasemos ahora a preguntarnos: ¿qué tipo de relaciones de interdependencia ha producido el capitalismo? ¿qué tipo de intercambios bio-ecológicos, qué imaginarios, qué politicidad y qué afectividad sostienen las tramas de interdependencia que se tejen desde la lógica del valor y qué implicaciones han tenido y siguen teniendo éstas para los pueblos de Abya Yala?

\section{Invención, cosificación y conquista de la naturaleza: la reorganización capitalista de la condición de interdependencia y su raíz antropocéntrica, patriarcal y colonial.}

No podemos comprender los actuales devenires, incluyendo nuestros presentes problemas, a no ser que incluyamos en el mismo a todos aquellos que fueron 'definidos como naturaleza' por los modernos patriarcas capitalistas: la Madre Tierra, las mujeres y las colonias. (Mies, 2018:154)

La irrupción de las relaciones capitalistas en la historia del mundo y su continua expansión sobre los cuerpos, los territorios y la trama de la vida en su conjunto, ha implicado históricamente, y sigue implicando en la actualidad, una reorganización violenta y permanente de las relaciones de interdependencia que sostienen la vida; una reorganización que es a la vez ecológica, biológica, política, 
simbólica y afectiva.

En diálogo con Navarro y Gutiérrez (2018) y con la lectura que De Angelis (2012) propone de Marx, sugiero pensar que la reorganización capitalista de la condición de interdependencia opera a partir de la reiteración de tres dinámicas simultáneas:

1. la instauración y reiteración constante (bajo formas históricamente renovadas y geográficamente diferenciadas) de la separación simbólica y material de hombres y mujeres de nuestros medios de existencia, y la consecuente fractura de relaciones sociales, biológicas y ecológicas correspondientes a formas sociales no-capitalistas (o no plenamente capitalistas);

2. la conversión de nuestra capacidad viva de trabajo y de nuestros medios de existencia en cosas explotables y valores independientes y ajenos a nosotros;

3. y la re-conexión y reorganización de lo inicialmente separado y cosificado, bajo los términos fijados por las mediaciones capitalistas (el estado, el mercado, el salario, la familia mononuclear, etc.) y las escalas espacio-temporales funcionales a la reproducción ampliada del valor.

A través de la reactualización de estas tres dinámicas a largo de la historia de la modernidad, la lógica capitalista de la valorización del valor ha logrado intervenir y re-organizar, de forma cada vez más profunda y totalizante, las relaciones de interdependencia, imponiendo sobre los cuerpos y los territorios patrones de organización de la vida que, en términos estrictamente bio-geoecológicos, generan bucles de retroalimentación profundamente biocidas. Como ha sido ampliamente estudiado y demostrado por distintas corrientes de la ecología, los patrones capitalistas de organización de la vida tienden a fracturar de manera sistemática los ciclos biológicos y las capacidades autoregulativas de los organismos vivos, de sus entornos y del planeta en su conjunto, enajenando y refuncionalizando las potencias autopoiéticas inscritas en los mismos.

En tal sentido, los términos de interdependecia planteados por los procesos de acumulación capitalista entran en una contradicción estructural con la vida en su conjunto, puesto que, al tiempo de plantear unos patrones de reproducción de la misma y vivir parasitariamente de ella, la destruyen de forma sistémica. La crisis bio-geo-ecológica que vivimos en nuestros presentes es la evidencia más dramática 
de ello.

Ahora bien, la relación contradictoria que la modernidad capitalista ha entablado con la vida tiene, en mi opinión, una raíz epistemológica y afectiva sobre la cual es necesario reflexionar, para poder plantear una crítica radical a la reorganización capitalista de la condición de interdependencia. En diálogo con Machado (sf), propongo pensar que dicha contradicción estructural se produjo en parte, se sostuvo en gran medida y se sigue sosteniendo en la actualidad, en la imposición de una profunda fractura epistémica en la historia de la humanidad y de sus múltiples y heterogéneas concreciones socio-culturales. Hablo de aquella fractura que se derivó de la imposición a escala mundial de la cosmovisión que subyace a la noción moderno-occidental de naturaleza y de la "inconmensurable degradación ontológica" que la Tierra (y el mundo no humano que la habita) sufrió en el momento en que dejó de ser considerado como un ser vivo, sagrado e interconectado, para convertirse en puro objeto explotable y susceptible de ser mercantilizado (Ibidem: 12).

De la mano de Frédérique Apffel-Marglin (2018) y Maria Mies (2018), entiendo que dicha fractura epistémica empezó a gestarse en la Europa del siglo XV a partir de la imposición de los primeros cercenamientos y de lo que la autora llama "el asesinato de Anima Mundi", es decir, del proceso histórico que llevó a la destrucción - por mano del estado, la inquisición y el pensamiento de los llamados filósofos naturales - de las cosmovisiones del campesinado oral europeo, en las que se compartía la idea de la existencia de un mundo vivo dotado de alma, donde todas las cosas - tanto humanas como no humanas - eran expresión de lo divino y mantenía una intima relación entre sí (APFFEL-MARGLIN, 2018: 9). Entre el siglo XV y el siglo XVII, a partir del suministro de inmensas dosis de violencia sobre los cuerpos y los territorios del campesinado europeo, las cosmovisiones que compartían tal noción de mundo fueron erradicadas violentemente en todo el viejo continente. Relegadas al mundo de la herejía; sepultadas bajo las cenizas de las hogueras que vieron en toda Europa la muerte de centenas de miles de campesinas y campesinos, junto con sus filósofos ocultos, sus médicos tradicionales y sus parteras: los herejes y las brujas de las iglesias católica y protestante de ese entonces (FEDERICI, 2015). 
Las "brujas", los sabios, los chamanes, los sascerdodes y los pueblos originarios de Abya Yala no gozaron de una mejor suerte. Como es bien sabido, los procesos de persecución y exterminio puestos en marcha por la Inquisición no se limitaron al territorio europeo, acompañaron el paso de los colonizadores y su avanzada sobre el continente Americano, donde la mayoría de los pueblos, pese a las profundas diferencias existentes entre ellos, compartían, al igual que el campesinado europeo, una visión de mundo en la que se reconocía la íntima relación que unía al ser humano con el cosmos y el entorno biótico y abiótico que habitaba; un entorno que en la mayoría de los casos poseía calidades anímicas que los colonizadores no tenían capacidad de comprender, ni mucho menos respetar.

Es así que, a partir de estos procesos históricos, tanto en Europa como en América (y en muchos otros lugares del mundo) las cosmovisiones que compartían una noción de un mundo vivo, "sagrado" e interrelacionado fueron progresivamente erradicadas y remplazadas por la imposición de otra cosmovisión: el llamado naturalismo. De la mano de Descolá (2012), entiendo al naturalismo como aquella cosmovisión que plantea una separación radical entre el ser humano y el llamado mundo natural, separación a partir de la cual pudo emerger y consolidarse el horizonte civilizatorio inscrito en la modernidad capitalista. El postulado principal sobre el cual se erige dicha forma de comprender y ordenar el mundo es, en efecto, la idea de que sólo los humanos están dotados de vida interior, los demás existentes - plantas, animales y materia inorgánica, es decir, todo aquello que es asociado con en mundo natural - están privados de la misma (DESCOLA, 2012) y, por tanto, pueden ser objeto de control y dominio por parte del ser humano. Dicho principio, cuya origen se encuentra en la teología judaicocristana, quedó claramente definido con la separación que Descartes, uno de los padres del pensamiento moderno y de la ciencia mecanicista, estableció entre res cogitans y res extensa, separación según la cual todo aquello que corresponde a la segunda (incluyendo el cuerpo humano) es convertido en un mecanismo inerte sin agencia (APFFEEL-MARGLIN, 2018) que responde a las leyes físico-químicas de la naturaleza y que, por tanto, es susceptibles de ser estudiado, viviseccionado, controlado y finalmente conquistado por las inmensas capacidades racionales del ser humano. Capacidades que por lo general fueron un privilegio ejercido históricamente por los que Mies llama "los 
modernos patriarcas capitalistas": hombres blancos propietarios.

El horizonte simbólico del naturalismo cosificó así a la naturaleza y decretó la primacía de lo humano sobre lo natural, estableciendo una relación dicotómica y jerárquica entre el ser humano (o mejor dicho el hombre blanco) y la naturaleza; y entre las calidades interiores del mismo (según el caso, la razón y/o el alma) y su cuerpo, su parte "natural".

Bajo este nuevo paradigma de comprensión del mundo, todo lo asociado con "lo natural" o con el "estado de naturaleza": mares y montes, ríos y praderas, plantas y animales, al igual que millones de cuerpos humanos reducidos a simple fuerza de trabajo (cuerpos mujeres, cuerpos indios, cuerpos negros, cuerpos niños, cuerpos esclavos) se transformaron en terreno de subordinación y conquista por parte del hombre moderno y occidental y de su nuevo amo: el mercado capitalista. La separación "hombre-naturaleza" y la noción de "naturaleza" que se deriva de la misma, se transformó en tal sentido en un poderoso dispositivo ${ }^{6}$ semántico de dominación, a partir del cual se fueron configurando un conjunto de separaciones dicotómicas y jerarquizadas funcionales a las dinámicas capitalistas de expropiación y explotación tales como la separación cultura-naturaleza, mente-cuerpo, pueblos civilizados-pueblos salvajes, hombre-mujer, etc. Tal como explica Horacio Machado (2014):

(...) la geocultura de la acumulación supone y se funda en la conquista y colonización de la naturaleza. Occidente hace da la "naturaleza" su primer, principal, y políticamente más redituable objeto de conquista. La articulación histórico-funcional entre el Estado, la Ciencia y el Capital conforma un poderoso aparato semiótico-político de producción de la realidad; con él se inaugura un nuevo modo de codificación, relacionamiento, apropiación y uso de la Naturaleza (p.10).

\footnotetext{
"Utilizo la noción de "dispositivo" en el sentido que Foucault buscó construir en torno a dicho concepto, en sus palabras: "Lo que trato de situar bajo ese nombre es, en primer lugar, un conjunto decididamente heterogéneo, que comprende discursos, instituciones, instalaciones arquitectónicas, decisiones reglamentarias, leyes, medidas administrativas, enunciados científicos, proposiciones filosóficas, morales, filantrópicas; en resumen: los elementos del dispositivo pertenecen tanto a lo dicho como a lo no dicho. El dispositivo es la red que puede establecerse entre estos elementos. En segundo lugar, lo que querría situar en el dispositivo es precisamente la naturaleza del vínculo que puede existir entre estos elementos heterogéneos. Así pues, ese discurso puede aparecer bien como programa de una institución, bien por el contrario como un elemento que permite justificar y ocultar una práctica, darle acceso a un campo nuevo de racionalidad. Resumiendo, entre esos elementos, discursivos o no, existe como un juego, de los cambios de posición, de las modificaciones de funciones que pueden, éstas también, ser muy diferentes. En tercer lugar, por dispositivo entiendo una especie -digamos- de formación que, en un momento histórico dado, tuvo como función mayor la de responder a una urgencia. El dispositivo tiene pues una posición estratégica dominante" (FOUCAULT, 1984: 1).
} 
Finalmente, a través de la construcción moderno-occidental de la noción de naturaleza y de su reducción a territorio de dominio y conquista, se instaura en el orden simbólico del mundo moderno capitalista un poderoso dispositivo de invisibilización de la violencia expropiatoria inscrita en la lógica de la acumulación y negación de las complejas relaciones de interdependencia que sostiene el tejido de la vida en los múltiples y diversos territorios del planeta.

Ahora bien, en la puesta en marcha por parte del mundo moderno occidental de esta gran empresa de invención y conquista de la "Naturaleza", el proceso histórico de colonización de América no fue, como ya mencionamos, un momento secundario de la historia; por lo contrario, representó un capítulo fundacional de la historia de la civilización moderno-capitalista. Parafraseando a Horacio Machado, podemos decir que, con la llegada de los españoles a las tierras-cuerpos de Abya Yala, se inaugura una nueva era geológica y civilizatoria (Machado, 2014: 65) marcada por la brutal explotación de las riquezas mineras del nuevo continente y por la radical trasformación en término capitalista de la economía mundial, transformación que fue posible a partir de la inyección de dichas riquezas en el mercado mundial. A lo largo de este proceso, la asociación de América a la noción de "Naturaleza" fue fundamental. Desde su invención (O'GORMÁN, 1986), América fue asimilada por los conquistadores al "estado de naturaleza", imaginada como un mundo sin civilización, primitivo, salvaje, animal, subdesarrollado, contenedor de riquezas infinitas y objeto obligado de explotación y conquista. En las palabras de Machado (2014):

Socialmente era imaginada como el ámbito de la barbarie, de la absoluta desnudez material y simbólica; geográficamente como el reino de la exuberancia cuyo exceso era un obstáculo para el desarrollo de la razón y el esfuerzo del trabajo. (...)

He aquí las representaciones dominantes a través de las cuales América fue inventada: su población bajo el signo de la ignorancia; su ambiente geofísico y su paisaje, como el contenedor de unas riquezas ilimitadas, inagotables; tan ricas que despertaban todas las codicias; tan generosas, que invitaban a la voraz tarea de una explotación también concebida infinita (Ibídem: 65-66).

Desde entonces, Abya Ayala, sus tierras, sus aguas, sus pueblos y las complejas relaciones de interdependencia bio-ecologícas, simbólicas, políticas y afectivas que éstos habían ido tejiendo a lo largo de siglos con sus territorios, con 
los elementos sagrados de los mismos, con los otros seres vivos, con el mundo de los espiritus y con el Cosmos en su conjunto, fueron sistemáticamente negadas; quemadas en la hoguera, torturadas, explotadas, extirpadas, arrancadas de sus epistemes, desectructuradas, relegadas al olvido, aunque nunca totalmente vencidas.

¿Cómo se pudo sostener y normalizar tanta violencia? ¿Cómo el proceso continuo e inacabado de invensión y conquista de la "Naturaleza" puesto en marcha por el proceso de acumulación capitalista ha marcado y sigue marcando las estructuras del sentir de nuestras sociedades? ¿Qué marcas ha dejado en las pieles del mundo en el que vivimos, en la dimensión política y afectiva de las tramas de interdependencia que se tejen y se destejen a través de los procesos de reorganización del tejido de la vida que la lógica de acumulación del capital impone una y otra vez sobre nuestros cuerpos-territorios?

No pretendo contestar a estas preguntas de forma exhaustiva en las pocas páginas que quedan de este artículo. Sin embargo, considero importante ponerlas sobre la mesa para avanzar desde allí en una crítica a la reorganización capitalista de la condición de interdependencia.

\section{Desafección y enajenación de lo político}

El capitalismo y su gran guerra de conquista contra la "Naturaleza" se sostiene, como ya dijimos, en un proceso permanente y en marcha de expropiación y explotación de inmensas cantidades de materia y energía extraídas de los cuerpos y los territorios de vastas regiones del planeta. Esta dinámica expropiatoria no sólo ha implicado y sigue implicando, tal como he argumentado arriba, una reorganización continua, violenta y biocida de los términos de interdependencia que sostienen la vida, también ha producido históricamente y sigue produciendo en la actualidad una multiplicidad de "dispositivos de regulación de las sensaciones y de las emociones" (SCRIBANO, 2009: 143) dirigidos a sujetar los cuerpos y generar subjetividades capaces de naturalizar y aguantar la violencia inscrita en este mundo hecho a medida del capital.

Un rasgo esencial de estas subjetividades adecuadas a las formas de vida capitalista y de las corporalidades que las encarnan es la interiorización de un 
profundo estado de desafección hacia lo que, en el imaginario colectivo, es asociado al mundo natural. Entiendo este estado de desafección como una condición sensorial y emotiva de insensibilidad ante las formas diversificadas y crecientes de devastación del tejido de la vida que las sociedades moderno-capitalistas han puesto en marcha.

Para sostener lo anterior, recupero la noción de desafección propuesta por Scribano (2007). El autor propone entender la desafección como una forma de expresión del dolor social en el que el sujeto alcanza un estado de "naturalización de las fuentes de dolor" y alta tolerancia social hacia el malestar. Escribe:

La repetición indefinida de un complejo de sensaciones de malestar provenientes de la existencia constante de condiciones sociales que generan impresiones de sufrimiento producen, finalmente, desafección. Es decir, un estado de "naturalización" de las fuentes de dolor que aumenta y hace cotidianos los volúmenes y estructura de unos sufrimientos determinados. La desafección implica el aumento de la tolerancia al malestar. Produce un "estado de aguante" de la fuente de dolor, generando el permanente "me da lo mismo", es decir, elaborando un contexto perceptual de aceptación del dolor. Esta es una lógica clara de coagulación de la acción, pues ese dolor ya no aparece como tal desde la fuente de donde proviene. (...) La exposición sostenida al dolor inicia una espiral entre parálisis, reproducción y olvido (SCRIBANO, 2007: 321).

La múltiple y secular violencia que ha acompañado desde sus orígenes la historia del capitalismo (violencia contra los territorios, contra otras matrices civilizatorias, contra los pueblos originarios, contra las mujeres, contra el trabajo vivo y contra todo aquello asociado a lo natural o "al estado de naturaleza") ha infligido sobre nuestros cuerpos inmensas dosis de dolor social que, como capas geológicas, se han ido sedimentando en las dimensiones más íntimas de nuestras sensibilidades. Me atrevo a sostener que la desafección hacia lo natural ha sido y sigue siendo una de las maneras en las que históricamente los sujetos modernos han procesado, o mejor dicho han renunciado a procesar, este dolor, anestesiándolo, naturalizándolo, aumentando cada vez más sus niveles de tolerabilidad, hasta volverse insensibles ante el mismo. Este estado emocional y sensorial representa una de las capas más profundas, sobre la cual se han erigido los cimientos de las estructuras del sentir de las sociedades capitalistas. Si la construcción moderno occidental de la idea de naturaleza puede ser pensada como un poderoso dispositivo semántico de invisibilización de la violencia expropiatoria, 
inscrita en la dinámica capitalista de acumulación y como un igualmente eficaz dispositivo de negación de las complejas relaciones de interdependencia que sostiene la reproducción de la vida humana y no-humana, el estado de desafección hacia lo natural que impregna las sensibilidades modernas representa de algún modo la contraparte sensorial de esta forma de codificación el mundo.

La fractura metabólica y epistémica que la lógica de la acumulación capitalista ha introducido en los vínculos existenciales, es decir, en los flujos energéticos y materiales que interconectan los cuerpos de vastas poblaciones del mundo consigo mismos y con multiplicidad de territorios, ha ido instaurando en la piel del mundo moderno-capitalista un estado emocional y sensorial de desconexión e insensibilidad ante las formas diversificadas de devastación del tejido de la vida que dicha lógica fomenta. Ha ido generando corporalidades incapaces de conectarse con el dolor que la violencia, inherente a los procesos capitalistas de reorganización continua y permanente de la condición de interdependencia, produce. En esa incapacidad de sentir radica, una de las formas más sutiles y profundas de enajenación y amputación de lo político que la dominación impersonal del capital ha implantado en las fibras más íntimas de nuestras sociedades.

Si entendemos lo político tal como he propuesto entenderlo en este texto, es decir, como la capacidad de los seres humanos de dar una forma singular, siempre contingente $\mathrm{e}$ inestable, a su socialidad $\mathrm{y}$ al conjunto de las relaciones de interdependencia que tejen con el entorno biótico y abiótico en y con el cual produce y reproduce su vida. Si entendemos que la dimensión afectiva al igual que la dimensión simbólica es una elemento esencial de la capacidad que las comunidades humanas tienen de forma a su socialidad y a las relaciones de interdependecia a través de las cuales reproducen sus existencias. Entonces entendemos también como el estado de desafección hacia lo natural que impregna las subjetividades modernas se vuelve un poderoso dispositivo de sujeción política y domesticación social.

Unos sujetos sociales incapaces de sentir el dolor social que produce la violencia inscrita en la dinámica capitalista de reorganización de la condición de interdependencia (por más que en algún caso puedan llegar a entender dicha dinámica racionalmente), son sujetos incapaces de establecer algún tipo de límite 
ante la reactualización continua de esa misma violencia. Son sujetos incapaces de elaborar dicho dolor, de nombrarlo, de transformarlo, de politizarlo, de entablar una relación diferente con "lo natural" y disputar otros formas de tejer la condición de interdependencia. En tal sentido, nuestra capacidad de sentir y, en ella, nuestra capacidad de elaboración del dolor, es un terreno de disputa permanente por parte del capital. $\mathrm{Y}$ es precisamente allí donde se juega una de las dimensiones más importante de las luchas en defensa de la vida que se despliegan hoy a lo largo y ancho de Abya Yala.

\section{La defensa de la vida más allá de la noción occidental de naturaleza y del estado de desafección: una hipótesis de trabajo a manera de conclusión.}

Abya Yala, la tierra grande y libre, el territorio ancestral donde milenariamente han convivido nuestras ancestras y ancestros, es la tierra que la colonización castellana nombró como continente americano o Latinoamérica, ese mismo territorio sigue en disputa por el patriarcado neoliberal del estado, empresarios, terratenientes y transnacionales, es un territorio donde se resiste la vida plural de los pueblos ante el mercantilismo de la naturaleza, es el lugar donde es posible recrear la vida desde otra propuesta, una propuesta de vida que convoca a interpelarnos, desde dónde hacemos el acuerpamiento, desde dónde nos situamos para indignarnos y para actuar en comunidad. Los pueblos indígenas defendemos la vida, porque concebimos que tenemos corresponsabilidad en proveer la energía vital en la Red de la Vida.

(Cabnal, Lorena: 2015)

La modernidad capitalista y los poderosos dispositivos semióticos, emocionales y políticos sobre los cuales se sostiene la visión de mundo que ésta impulsa, han fracturado profundamente las epistemes y los flujos de interdependencia energéticos y materiales que unían a los pueblos indígenas y campesinos de Abya Yala, Europa y el mundo entero con sus cuerpos-territorios, condenándoles y condenándonos a asumir en gran medida los términos de interdependencia impuestos por el mercado. Hoy en día, dicha fractura, al igual que la violencia inscrita en la dinámica capitalista de acumulación, se re-actualiza y se profundiza en cada acto de despojo, en cada proyecto de explotación, en cada represa, en cada mina, en cada "proyecto de muerte" que el capital busca imponer sobre los cuerpos-territorios de nuestro continente. Sin embargo, junto con ellas, también se reactualiza la lucha, y la tenaz y persistente capacidad de los pueblos indígenas y campesinos de Abya Yala por no dejar de ser lo que son y han sido; por 
defender, en medio de la condición de la fragmentación que los atraviesa, sus territorios, sus saberes tradicionales, sus modos de vida y sus sentidos de mundo.

Un eje trasversal a muchas de las luchas que han sacudido el continente en las últimas décadas ha sido la capacidad de producir un sentido común de disidencia que sitúa la defensa de la vida en el centro del antagonismo social. Sin embargo, la vida que se defiende no es la vida en abstracto, la vida en singular, desgarrada por las separaciones capitalistas, al que nos condena el mundo individualizante y cosificante del capital; sino todo lo contrario, es la vida en plural de los pueblos y de los territorios que éstos habitan. Es un entramado complejo en torno al cual se tejen muchas formas de vidas y muchos sentidos de vida, a la vez. Es, simultáneamente, la multiplicidad de tramas de interdependencia que sostiene el tejido de la vida de los distintos territorios de Abya Yala; los modos de vida históricos y concretos que los pueblos han tejido con los entornos bióticos y abióticos en y con los cuales han aprendido a reproducir sus existencias; las relaciones metabólicas, simbólicas y afectivas que han ido tejiendo a lo largo de la historia con sus ríos, con sus cerros, con sus bosques, con sus tierras y con los espíritus que los habitan; las formas políticas comunitarias a través de las cuales han aprendido a auto-organizarse en colectivo; el legado de los ancestros, la memoria viva de los muertos, el pasado que clama justicia y el pasado-presente del dolor infligido sobre los cuerpos humanos y no humanos que se resisten a dejar de sentir y disputar por otros sentidos de vida más allá de los impuestos por el mundo moderno-capitalista.

Me atrevo a hipotizar a manera de conclusión de este artículo y de apuesta investigativa para el futuro, que el sentido de vida que emerge en muchas de las luchas que se despliegan hoy a lo largo y ancho de Abya Yala, al igual que los sentimientos y las estructuras colectivas del sentir que éste moviliza, ponen radicalmente en crisis la noción moderno-capitalista de naturaleza y su construcción como dispositivo de sujeción social, ofreciéndonos la posibilidad civilizatoria de descolonizar nuestras sensibilidades y desplazar nuestras subjetividades hacia otras formas de codificar y sentir el mundo. Este desplazamiento pasa en gran medida por la capacidad que estas luchas han tenido de resquebrar el estado de desafección hacia lo natural que impregna las subjetividades modernas y abrir, por 
lo menos al interior de las comunidades que están sosteniendo tales luchas, otros caminos de verbalización, reconocimiento, procesamiento, puesta en común, politización y transformación del dolor social inscrito históricamente en la violencia expropiatoria que la dinámica capitalista de reorganización de la condición de interdependencia ha infligido y sigue infligiendo sobre los cuerpos humanos y nohumanos de vastos territorios del continente. En esa capacidad, reside una de las potencias transformadoras más cruciales para el futuro de Abya Yala y del planeta. Explorarla, documentarla, desentrañarla, representa sin duda un gran desafío para el pensamiento crítico latinoamericano.

\section{Referencias}

AMHED, S. La política de las emociones. México D.F.: PUEG/UNAM, 2015.

APFFEL-MARGLIN, F. La colonialidad de las raíces de la modernidad occidental. Ponencia presentada en la Primera Conferencia Nord-Sur sobre Decrecimiento, Ciudad de México, 3-7 de septiembre de 2018.

CABNAL, L. En el país más verde y feliz del mundo, los pueblos originarios Iloran su Abya Yala usurpada, 2015. Disponible en: https://censat.org/es/analisis/en-el-pais-mas-verde-y-feliz-del-mundo-los-pueblosoriginarios-lloran-su-abya-yala-usurpada-4330. Acceso en 22 agos. 2019.

CAPRA, F. La trama de la vida. Una perspectiva de los sistemas vivos. Barcelona: Editorial Anagrama,1999.

DE ANGELIS, M. Marx y la acumulación primitiva: el carácter continuo de los 'cercamientos' capitalistas. Theomai n.26. Buenos Aires, 2012.

DESCOLÁ, P. Más allá de la naturaleza y la cultura. Barcelona: Amorrortu Editores, 2012.

ECHEVERRÍA, B. Valor de uso y utopía. México D.F.: Siglo XXI, 1999.

ECHEVERRÍA, B. Definición de la cultura. México D.F.: Itaca/UNAM, 2001.

FEDERICI, S. Calibán y la Bruja. Mujeres, cuerpo y acumulación originaria. México D.F.: Pez en el Arbol/Tinta Limón, 2015.

FOUCAULT, M. El juego de Michel Foucault (entrevista a Michel Foucault), 1984. Disponible en: ricardobur.com.ar, biblioteca, El juego de Michel Foucault.Consulta 2 jun. 2019. 
GIL, S. Nuevos feminismos. Sentidos comunes en la dispersión. Una historia de trayectorias y rupturas en el Estado español. Madrid: Traficantes de Sueños, 2011.

GUTIÉRREZ, R.; Linsalata, L.; Navarro, M. Repensar lo político, pensar lo común. Claves para la discusión. In: Inclan, D.; Linsalata, L.; Millán, M. (Coords). Modernidades alternativas. México D.F.: UNAM, 2017.

HERNÁNDEZ, F. J. Vida, muerte y lucha en la Sierra Norte de Puebla. Una reflexión en torno a la Asamblea de los Pueblos Maseual, Totonaku y Mestizo en Defensa de la Vida y el Territorio. Tesis (Maestro en Sociología). Benemérita Universidad Autónoma de Puebla, Puebla, 2019.

HERNANDO, A. La fantasía de la individualidad. Sobre la construcción sociohistórica del sujeto moderno. Madrid: Katz Editores, 2012.

MACHADO A. H. Las herencias de Occidente. Crisis ecológica, colonialismo y hambre, $\quad$ (sf). Disponible en: https://www.academia.edu/11872485/Las_herencias_de_Occidente. Consulta 10 feb. 2019.

MACHADO, A. H. Potosí, el origen. Genealogía de la minería contemporánea. Buenos Aires: Mardulce, 2014.

MACHADO, A. H. Territorios y cuerpos en disputa: extractivismo y ecología política de las emociones. Intersticios. Revista sociológica de pensamiento crítico, Vol.8. N1, 2014a. Disponible en: http://www.intersticios.es/article/view/11288.

MIES, M. Patriarcado y acumulación a escala mundial. Madrid: Traficantes de sueños, 2018.

NAVARRO T. M. Despojo múltiple sobre el tejido de la vida: impactos y resistencias socio-ambientales. Revista Textual n.73. México D.F.: Universidad de Chapingo, 2017.

NAVARRO T. M.; Gutiérrez, R. Claves para pensar la interdependencia desde la ecología y los feminismos. Revista Bajo el Volcán n.28. Puebla: ISCyH-BUAP, 2018.

PÉREZ, O. A. Subversión feminista de la economía. Aportes para un debate sobre el conflicto capital-vida. Madrid: Traficantes de Sueños, 2014.

SÁNCHEZ G. M. In Sabino Sánchez, Fernando. Poetas del siglo XXI - Antología mundial, 2013.2 Disponible en: https://poetassigloveintiuno.blogspot.com/2013/06/mikeas-sanchez-10066.html. Consulta 2 feb. 2019.

SUAREZ L. A. L. La dimensión sensible de lo político. In: Gutiérrez, Raquel, 
Comunalidad, tramas comunitarias y producción de lo común en América Latina. México: Pez en el Arbol / Casa de las preguntas,2018.

SCRIBANO, A. Mapeando Interiores. Cuerpo, Conflicto y Sensaciones. Argentina: CEA-UNC / Jorge Sarmiento Editor, 2007.

SWYNGENDOUW, E. ¡La naturaleza no existe! La sostenibilidad como síntoma de una planificación despolitizada. Urban N.1, Los futuros de la planificación. Madrid: Universidad Politécnica de Madrid, 2011.

WILLIAMS, R. Marxismo y literatura. Barcelona: Península, 1980. 